\title{
SOFT TISSUE ESTHETICS IN IMPLANT DENTISTRY
}

\author{
Rakesh V. Somanathan ${ }^{1}$, Antonín Šmůnek ${ }^{1}$, Josef Bukač², Tomáš Brázda ${ }^{1}$, Dana Kopecká ${ }^{1}$
}

Charles University in Prague, Faculty of Medicine in Hradec Králové and University Hospital Hradec Králové, Czech Republic: Department of Dentistry ${ }^{1}$, Department of Medical Biophysics ${ }^{2}$

\begin{abstract}
Summary: Dental implants have been considered to be a successful treatment modality. Recently, achieving a good osseointegration is not the ultimate goal for the restorative dentist. Successful implant treatment demands the best gingival esthetic success along with stability and function of the implant. This study was performed to obtain answers to some controversial points pertaining to esthetics and function of implants in maxilla. Immediate flapless implantation into the extraction sockets in maxillary anterior zone is an emerging treatment option in dentistry- the esthetic success of which was in debate for long. The proposed study compared the esthetic success of immediate flapless implants (ILA), to immediate implants with the need for flap (ILB) and, delayed implants (DSL) in single tooth restorations, in the anterior region of the maxilla. The other aim of the study was to find out if any relation exists between the interproximal crestal bone height and papilla height. Analysis was done irrespective of treatment procedure in the same study group using periodontal sounding and radiographs to find out the relation. From the study involving 106 participants, including 21 ILA, 22 ILB and 63 DSL cases, we received highest papillary index score of 2.6 average from group ILA, followed by ILB and DSL, after 3 months of prosthetic loading. From the periodontal sounding and radiographic study it was evident that, when the distance between the base of the contact point of crowns and height of interproximal bone was less than 5, the papilla was present $100 \%$ of the time, but when the distance increased to 6 and more than $7 \mathrm{~mm}$, the papilla was present only 46.5 and 24 percentage of the time respectively.
\end{abstract}

Key words: Dental implants; Esthetics; Papilla; Papillary index

\section{Introduction}

Developments of restorative dentistry made dental implants an integral part in restorative dentist's armamentarium. The recent concepts of implant dentistry is not restricted to the basic needs, but has evolved to cosmetic or esthetic corrections to uplift the self-esteem and confidence of Man. As the predictability of dental implants has been proved beyond doubt, achieving a good success rate in terms of stability is no longer a big concern among dentists, but esthetic success of therapy is also a major concern now. The anterior maxillary teeth in the 'esthetic zone' usually extend from first premolar to first premolar, but in some individuals can extend as far distally as the first molar (10). Esthetics is, to a great extent, determined by the level and appearance of the periimplant soft tissues, including the shape of the papillae. Maintaining the interdental papilla and bone height following implant placement has been a challenge for the restorative dentist. The presence or absence of the interdental papilla associated with multiple adjacent implants may be affected by the amount of alveolar bone loss prior to implant placement, distance between adjacent implants, position of implants in relation to adjacent teeth, as well as the subgingival contours of the implant-supported restoration (12).

Many surgical techniques have been developed attempting to regenerate interdental papillae $(3,4)$. Unfortunately, no single technique offers consistent clinical success. In modern implantology, various surgical and non-surgical techniques have developed to achieve optimal results in the preservation and regeneration of interdental papilla. To verify these results, different methods of measuring the lengths of papilla have been introduced. Bone probing has been confirmed as a valid method of reporting the papilla length (25). The principle aims of this study were to assess implant esthetic success from three different treatment protocols of implant placement, by evaluating the interdental papilla as the key and also to analyze if there is any specific relationship existing between crestal bone height and interdental papilla fill.

\section{Materials and methods}

One hundred and six patients, partially edentulous in the maxilla in the region from first premolar to first premolar (esthetic zone) were enrolled in this prospective, cross-sec- 
tional study. One hundred and eighty-five interdental and interimplant papillae were evaluated using Papilla Presence Index (14) and one hundred and fifty sites were evaluated radiographically. The rest of twenty-seven papillae (was either involved in infection from adjacent tooth) were discarded due to other reasons. The patients were informed of the options for tooth replacement including the risks and benefits of dental implants. Following a thorough review of medical and dental histories, description of the clinical procedures, and financial arrangements, informed consent was obtained. Eighty-two endosseus screw form implants were inserted in various locations in the esthetic zone in maxilla, at Implantology Center, Department of Dentistry, in the University Dental Hospital. The lengths and diameters of the individual implants vary depending on the amount of available bone. Patients were divided in three categories according to clinical presentation and type of treatment provided - immediate reconstruction (ILA), which included patients presented with a single tooth indicated for extraction, when only the tooth is compromised and not the soft tissue and surrounding osseous structure. The second group included patients with healed/partially edentulous area with good bone quality and was treated with immediate loading, implants placed with raising a flap (ILB). The third category of patients included the delayed loading cases, which were loaded after 3 months from the date of implantation (DSL). In the mean time the implant was secured in place with a cover screw and flaps with tension free sutures. In a second stage surgery a punch technique was performed to expose the fixture and a healing abutment was placed. This was replaced by a definitive crown after 14 days.

Inclusion criteria for study included adequate oral hygiene, older than 16 years, do not smoke more than 10 cigarettes per day, absence of residual root and local inflammation, no history of local radiation therapy, adequate bone volume and absence of any serious systemic diseases, which would jeopardize bone healing.

Esthetic success was evaluated using Jemt's Papillary Presence Index (14). The papillary index designates five different levels of papilla height $(0=$ no papilla, $1=$ papilla present below one third of interdental space, 2 = papilla fill till two third of the interdental space, $3=$ interdental area filled with papilla, $4=$ papillary hypertrophy). Measurements were made from the reference line connecting the highest gingival curvatures of the implant crown restoration and the adjacent tooth or crown on the buccal side. The mesial and distal papillae were evaluated for completeness, incompleteness, or absence. A photograph of the area was taken and kept for future reference. Average of the scores from two blind observers were taken and rounded off to nearest full digit.

In order to understand the relation of papilla fill and crestal bone level, few patients were enrolled into the second part of the study. In those cases periodontal sounding was done after administration of anesthesia for measurement of the level of crestal bone. In most of the cases a con- trol radiograph (intra oral periapical radiograph) was taken. The distance from the base of contact point of crown and the crest of the crestal bone was also measured from this radiograph to reduce margin of error.

All implants were placed in a similar manner. Briefly, implants were placed in the optimal three-dimensional position: apico-coronally, $2-3 \mathrm{~mm}$ below the adjacent CEJ line (20); bucco-lingually, 3-4 $\mathrm{mm}$ from the outside buccal flange (15); and mesio-distally, $\geq 1.5 \mathrm{~mm}$ away from adjacent teeth (18).

Evaluation of contingency table (PPI index measurements) was done by Fisher's test. Statistical mean was used to compare between groups. Significance was determined by a p-value less than 0.05 .

\section{Results}

The mean age of the subjects was $29 \pm 15.5$ (mean \pm SD) years ranging from 17 to 68 years. 51 females and 55 males took part in the study. Most implants (76 of 106) were placed in maxillary incisor region, 21 in canine region and 9 in premolar region. Size of implants ranged from 3.7 $\mathrm{mm}$ diameter to $5.0 \mathrm{~mm}$ diameter and length from $12 \mathrm{~mm}$ to $16 \mathrm{~mm}$ irrespective of site. The overall implant survival rate was $100 \%$ in each group.

Number of papillae measured was 177 (86 mesial and 91 distal) and number of marginal gingival level measured was 64 (DSL 28; ILA 20; ILB16). The ILA group showed the highest score with a maximum 3 and minimum 2 score. The lowest score was recorded in the DSL category. As expected, the ILA group secured a high PPI score compared to other two cohorts (mean 2.6 for mesial papilla and 2.7 for distal) and DSL secured the least (mean 1.52 for mesial papilla and 1.73 for distal papilla). The respective scores are given in Tab. 1.

Tab. 1: Mean values of Papilla indices (PPI) for different groups.

\begin{tabular}{|l|c|c|c|c|}
\hline \multirow{2}{*}{ Mean } & \multicolumn{4}{|c|}{ Group } \\
& ILA & ILB & DSL & Total \\
\hline Mean of PPI (M) & 2.6 & 2.4 & 1.5 & 2.2 \\
\hline Mean of PPI (D) & 2.7 & 2.3 & 1.7 & 2.2 \\
\hline
\end{tabular}

$\mathrm{M}=$ mesial; $\mathrm{D}=$ distal

Tab. 2: Relationship between crestal bone level and PPI index score (Crestal bone level vs. papilla fill).

\begin{tabular}{|l|c|c|c|}
\hline \multirow{2}{*}{ PPI } & \multicolumn{3}{|c|}{$\mathrm{X}(\mathrm{mm})$} \\
& $\leq 5$ & 6 & $\geq 7$ \\
\hline 3 & 100 & 46.5 & 24 \\
\hline $0-2$ & 0 & 53.5 & 76 \\
\hline
\end{tabular}

$\mathrm{X}(\mathrm{mm})$ - distance between the bases of the contact point of implant supported crown and crown of adjacent tooth in millimeters. PPI - papillary index scores. Results given in percentage value (\%). 
The group ILA secured a mean papilla score (30\%) much higher than the group average $(25 \%)$. Other cohorts secured score $27 \%$ (ILB) and $25 \%$ (DSL) respectively. Mesial and distal papillae secured similar scores according to Fisher's test or in other words, the probabilities to obtain a similar score for mesial and distal papilla was same ( $p=$ 0.74939). Therefore when mesial and distal PPI scores were compared against different groups of crestal bone levels, a definite relationship between them could be elucidated. 92 sites were evaluated and 31 of them scored less than $5 \mathrm{~mm}$ from crestal bone height to the base of contact point, 31 scored $6 \mathrm{~mm}$, and the remaining 30 had distances exceeding or equal to $7 \mathrm{~mm}$. When the distance between heights of the crestal bone to the base of the contact point of the restoration (X) was evaluated, a definite relation was obtained. Respective data are given in Tab. 2. The values of $\mathrm{X}$ were rounded off to the nearest integer.

\section{Discussion}

Soft tissue management is one of the many factors that have a heavy impact on the final esthetic result, with the need to harmonize color, form, and contour with that of the adjacent tissues (8). In the study the factors, which affected the clinical outcome, were mainly the labial bone integrity and height (in flapless immediate loading especially) and soft tissue level. Bone resorption, as much as 3 to $4 \mathrm{~mm}$ occurs during the first 6 months post-extraction, compromising the bone and gingival tissue levels for the implant placement and subsequently leading to loss of peri-implant papillae $(1,6)$. Therefore, the most effective means to recreate a papilla was to prevent the loss of the underlying bone at the time of tooth removal. For single-tooth replacement, the interproximal level of the bone is important in the maintenance of the interproximal papilla. "Atraumatic" extraction was done using forceps rotation and periotomes, without damaging the surrounding bony wall followed by immediate placement of a root form implant (27).

Our study included screening of 106 potential implant sites for papilla score and marginal gingival height. From the results it was evident that immediate flapless implantation secured a high score compared to other two groups,

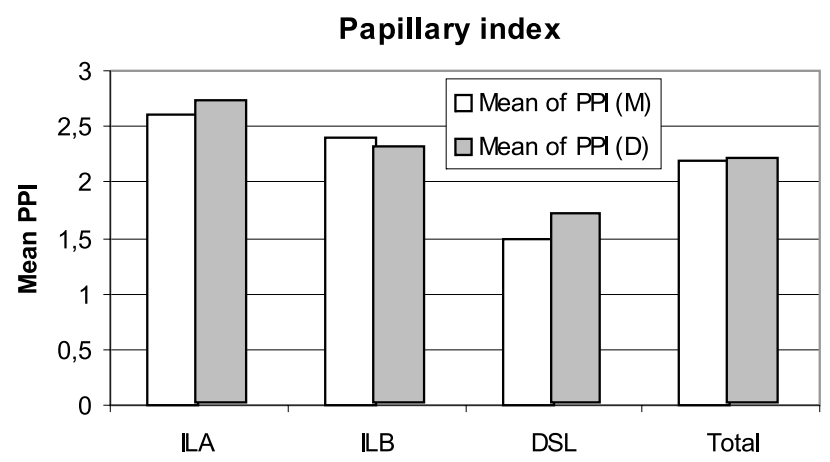

Fig. 1: Mean papillary index (PPI). making it the most successful treatment strategy (Fig. 1). Placement of implants at the time of extraction has become a predictable method $(5,11,23)$. In the study, selected cases (ILA) were treated with immediate implantation without the need of raising a flap and all of them survived the first three months of loading. Since the early start of this centuary flapless surgery has been suggested as a treatment modality for the preservation of the soft tissue and for increasing patient comfort and satisfaction $(2,19)$. An estimate of $25 \%$ decrease in faciopalatal width occurs within the first year $(9,17,24)$. For this reason, within the last decades, the 'gold standard' implant treatment protocol has been challenged by experiments, which aimed at shortening the treatment period and by reducing the number of surgical procedures. All the cases included in the ILA category, had enough bone volume for implantation and good marginal soft tissue level. Clinical studies demonstrated that the immediate implant placement reduces alveolar resorption $(16,27)$. Moreover, this surgical procedure also allows a better final rehabilitation because it facilitates both morphological ridge contour preservation and accurate prosthetic implant installation, maintaining the natural tooth angle (26). There are also important benefits because the treatment time is reduced. Indeed, alveolar wound healing coincides with implant osseointegration and the patient can achieve the reinstatement of his edentulousness swiftly and by means of a single surgical exposure (21). The reason that the immediate flapless protocol secured a high esthetic score can also be pertained to other factors. There has been a report of postsurgical tissue loss from flap reflection, implying that flap surgery for implant placement may negatively influence implant esthetic outcomes, especially in the anterior maxilla.

In the presurgical planning stage, the decision to proceed with any soft tissue grafting should be made before or after implant placement depending on the presence of a stable keratinized band. Holmes observed, "interdental papilla does not regenerate after loss of its osseous support”. Surgical techniques using soft tissue management alone to reproduce the interimplant papilla do not give a predictable result (13). In the present study also, a definite relation between the two was found. A classic study conducted by Tarnow et al. (25) correlated the presence or absence of the interproximal papilla with the distance from the contact area to the crest of the bone in human dentition. This analysis revealed that the papilla was present almost $100 \%$ of the time when the distance was $\leq 5 \mathrm{~mm}$; when the distance was $6 \mathrm{~mm}$, the papilla was present $56 \%$ of the time; and when it was $\geq 7 \mathrm{~mm}$, the papilla was present only $27 \%$ of the time or less. But, this study was done for natural dentition. Later in 1998, Salama et al. (22) suggested a similar relationship in implant therapy. In our study, a similar relation was found. When the distance between the base of the contact point of crowns and height of interproximal bone $(\mathrm{X})$ was $\leq 5 \mathrm{~mm}$, the papilla was present $100 \%$ of the time, but when the distance increased to 6 and 
$\geq 7 \mathrm{~mm}$, the papilla was present only 46.5 and 24 percentage of the time. Therefore on the literature, and the present study it can be said that, the presence of papillae is affected by the level of the alveolar crests below in the interdental space and the relationship between the vertical dimension of the interdental space and the presence of papillae $(7,22,25)$.

\section{Conclusions}

Immediate flapless reconstruction of tooth loss in the anterior maxillary area is esthetically the best treatment procedure compared to delayed loaded implants and immediate implants placed after elevating a flap. The papilla length and height of interproximal crestal bone is related to each other in a directly proportional way.

\section{Acknowlegments}

The authors would like to thank doc. MUDr. Věra Hubková, CSc., Head of the Department of Dentistry, for her help in reviewing and publishing this manuscript.

\section{References}

1. Atwood DA, Coy DA. Clinical cephalometric and densitometric study of reduction of residual ridges. J Prosthet Dent 1971;26:280-93.

2. Auty C, Siddiqui A. Punch technique for preservation of interdental papillae at nonsubmerged implant placement. Implant Dent 1999;8:160-6.

3. Beagle JR. Surgical reconstruction of the interdental papilla: case report. Int J Periodont Rest Dent 1992;12:145-51.

4. Becker W, Becker BE. Flap designs for minimization of recession adjacent to maxillary anterior implant sites: a clinical study. Int J Oral Maxillofac Implants 1996;11:46-54.

5. Becker W, Dahlin C, Lekholm U, Bergstrom C, van Steenberghe D, Higuchi K, Becker BE. Five-year evaluation of implants placed at extraction and with dehiscences with ePTFE membranes. Results from a prospective multicenter study. Clin Impl Dent Relat Res 1999;1:27-32.

6. Chiche GJ, Block MS, Pinault A. Implant surgical template for partially edentulous patients. Int J Oral Maxillofac Implants 1989;4:289-92.

7. Choquet V, Hermans M, Adriaenssens $P$ et al. Clinical and radiographic evaluation of the papilla level adjacent to single-tooth dental implants. A retrospective study in the maxillary anterior region. J Periodontol 2001;72:1364-71.
8. Croll BM. Emergence profiles in natural tooth contour. Part I: Photographic observations. J Prosthet Dent 1989;62:4-10.

9. deLange GL. Aesthetic and prosthetic principles for single tooth implant procedures: an overview. Pract Periodontol Aesth Dent 1995;7:51-61.

10. Elias AC, Sheiham A. The relationship between satisfaction with mouth and number and position of teeth. J Oral Rehab 1998;25:649-61.

11. Gelb DA. Immediate implant surgery three-year retrospective evaluation of 50 consecutive cases. Int J Oral Maxillofac Implants 1993;8:388-99.

12. Grossberg DE, Interimplant papilla reconstruction: assessment of soft tissue changes and results of 12 consecutive cases, J Periodontol 2001;72:958-62.

13. Holmes CH. Morphology of the interdental papillae. J Periodontol 1965 36:21-26.

14. Jemt T. Regeneration of gingival papillae after single-implant treatment. Int $\mathrm{J}$ Periodont Rest Dent 1997; 17:327-33.

15. Kazor CE, Al-Shamari K, Sarment DP et al. Implant plastic surgery: a review and rationale. J Oral Implantol 2004;30:240-54.

16. Lazarra RJ. Immediate implant placement into extraction sites: surgical and restorative advantages. Int J Periodontol Rest Dent 1989;3:333-43.

17. Misch CE. Divisions of available bone in implant dentistry. Int J Oral Implantol 1990;7:9-17.

18. Ohrnell LO, Hirsch JM, Ericsson I, Branemark PI. Single-tooth rehabilitation using osseointegration: a modified surgical and prosthodontic approach Quintessence International. Sao paulo 1988;19:871-6.

19. Rocci A, Martignoni M, Gottlow J. Immediate loading in the maxilla using flapless surgery, implants placed in predetermined positions, and prefabricated provisional restorations: A retrospective 3-year clinical study. Clin Implant Dent Relat Res 2003;5:29-36.

20. Saadoun AP, Landsberg TC. Treatment classifications and sequencing for post extraction implant therapy: a review. Pract Periodontol Rest Dent 1997;9: 933-41.

21. Saadoun AP, Missika P, Denes L. Immediate placement of an implant after extraction: indications and surgical requirements. Actualites Odontostomatologiques 1990;171:415-35.

22. Salama H, Salama MA, Garber D, Adar P. The interproximal height of bone: a guidepost to predictable aesthetic strategies and soft tissue contours in anterior tooth replacement. Pract Periodont Aesthet Dent 1998;5:1131-41.

23. Schwartz-Arad D, Chaushu G. Placement of implants into fresh extraction sites 4 to 7 years retrospective evaluation of 95 immediate implants. J Periodontol 1997:68:1110-16

24. Tallgren A. The continuing reduction of the residual ridges in complete denture wearers: a mixed-longitudinal study covering 25 years. J Prosthet Dent 1972; 27:120-32.

25. Tarnow DP, Magner AW, Fletcher P. The effect of the distance from the contact point to the crest of bone on the presence or absence of the interproximal dental papilla. J Periodontol 1992;63:995-6.

26. Werbitt MJ, Goldberg PV. The immediate implant: bone preservation and bone regeneration. Int J Periodont Rest Dent 1992;3:206-17.

27. Wheeler SL, Vogel RE, Casellini R. Tissue preservation and maintenance of optimum esthetics: a clinical report. Int J Oral Maxillofac Implants 2001;2: $265-71$

Submitted May 2007.

Accepted June 2007.

\section{Corresponding author:}

Dr. Rakesh V. Somanathan, University Hospital, Department of Dentistry,

Sokolská 581, 50005 Hradec Králové, Czech Republic, e-mail: drrakesh81@gmail.com 